\title{
Transverse Preputial Island Flap for Hypospedias Repair: A Study in A Tertiary Level Hospital
}

\author{
Hafiz Al-Asad ${ }^{1}$, Md. Selim Morshed ${ }^{2}$, Tasnim Alam Manzer ${ }^{2}$, Abu Naser Md. Lutful Hasan ${ }^{4}$, Zulfia Zinat \\ Chowdhury $^{5}$, AKM Shahadat Hosain ${ }^{6}$
}

Received: 08 - 08 - 2020

Accepted: 20 - 10 - 2020

Conflicts of interest: None

Keywords: Hypospadias, Transverse Preputial Island Flap (TPIF) urethroplasty, Urethrocutaneous fistula.

\begin{abstract}
:
Introduction: Hypospadias continues to be a challenging problem for reconstructive surgeon. As urethral plate preservation got an important role, transverse preputial island flap (TPIF) urethroplasty is one of the preferred technique for sub-coronal and distal penile hypospadius.
\end{abstract}

Methods: This study was conducted at urology department, DMCH, from February, 2014 to June, 2017 where 15 patients underwent TPIF urethroplasty. Inner preputial flap with its pedicle was developed and separated from the dorsal penile skin which was sutured to the urethral plate in an onlay manner over a stent by running suture. Glanuloplasty and meatoplasty was done and skin closed.SPC was done in every cases. Dressing was checked on $5^{\text {th }} P O D$, stent was removed after 03 weeks. SPC was removed 2 to 3 days after satisfactory voiding. All patients were followed up at $6^{\text {th }}$ and 12 th week.

Results: Among the 15 patients age range was 2-14 years and mean age. Sub-coronal in 4 and distal penile was in 11 patients. Following TPIF urethroplasty wound disruption was noted in one patient for that glans closure was done successfully. There was no meatal stenosis and urethrocutaneous fistula in follow up. Regarding cosmetic outcome 12 were good, 2 were acceptable and 1 was poor.

Conclusion: Success rate of TPIF urethroplasty in case of sub-coronal and distal penile hypospadias is excellent. Cosmetic outcome should be considered most challenging and with experience of surgeons this aspect will be improved.

\section{Introduction:}

Hypospadias is a challenging problem for reconstructive surgeons to restore normal function and appearance. Many techniques to repair hypospadias have been reported, no consensus has yet been made on the best repair. Hence, surgical techniques for hypospadias repair are continuously being developed,

1. Assistant Professor, Department of Urology, DMCH, Dhaka

2. IMO, Department of Urology, RpMCH, Rangpur, Rangpur

3. Resident, Department of Urology, DMCH, Dhaka

4. Assistant Registrar, Department of Urology, DMCH, Dhaka

5. MO, Department of Haematology, NICRH, Dhaka

6. Professor, Department of Urology, DMCH, Dhaka

Correspondence: Dr. Hafiz Al-Asad, Assistant professor, Department of Urology, Dhaka Medical College Hospital, Dhaka1000, Bangladesh Email: hafizalasad34@yahoo.com aiming to overcome the available methods. Now-adays, particular importance has been given to urethral plate preservation because urethral plate is well vascularized, has a rich nerve supply and muscular backing and gland formation. ${ }^{1}$ Transverse preputial island flap (TPIF) urethroplasty and tubularized incised plate urethroplasty (TIPU) are two preferred techniques where urethral plate is preserved. ${ }^{2}$

The tubularized incised plate urethroplasty (TIPU) as described by Snodgrass has become the preferred technique for distal hypospadias repair, and gained world-wide popularity and acceptance. ${ }^{2}$ Snodgrass himself found overall complication rate of $8 \%$ and UCF $4 \%{ }^{3}$ Transverse preputial island flap urethroplasty (TPIF) repair for hypospadias was originally advocated 
by Asopa and further developed and popularized by Duckett. It is based on superficial dorsal vessels of the penis which is still a popular method. ${ }^{4,5}$ It can be applied to anterior, mid and posterior penile hypospadias.

The complication rate varies with the complexity of the repair and the surgeon's experience level. ${ }^{6}$ The most common complications other than urethrocuteneus fistula include meatal stenosis, persistent chordee, infections, wound disruption, unacceptable cosmetic outcome, urethral stricture etc. ${ }^{7}$ This study was conducted to describe the results of (TPIF) urethroplasty at our department in respect of complication and cosmetic outcome.

We strongly believe first attempt of surgery has the highest outcome. If complication occurs after first attempt of hypospadias surgery, more surgeries are needed and still the result may not be optimal.

\section{Methods:}

The study was a prospective experimental study. This study was conducted at the Department of Urology, Dhaka Medical college Hospital from 2014 to 2017. During this period 18 patients were selected. Detailed history regarding pattern of urinary stream, clinical examination regarding the shape of glans penis, location of urethral meatus, chordee, condition of urethral plate, condition of prepuce, testis, hernia was performed. Investigation related to anesthetic fitness, ultrasonography of kidneys ureters and bladder region and Urine R/M/E and C/S was done.

During surgery, a subcoronal incision was made encircling the glans and continued around the urethral plate, the penile skin was degloved preserving the urethral plate. Artificial erection test was performed and if chordee present it was corrected by dorsal plication. Glans wings were mobilized, and the inner preputial flap with its pedicle was developed and separated from the dorsal penile skin. The flap was then sutured to the urethral plate in an onlay manner over a stent by running 5/0 Vycril suture. Redundant tissue from the pedicle is tacked over the suture lines with interrupted suture. Glanuloplasty and creation of meatus was done. Then skin closure done in layers. In all cases stented urethroplasty was done and urinary diversion was done with suprapubic cystostostomy.

Dressing was checked on $5^{\text {th }}$ POD. Wound infection, disruption and surrounding skin condition was observed. Stent was removed after 03 weeks. Then voiding information, caliber of the urinary stream was observed and any other complications were noted. At the same time cosmetic appearance was noted. SPC was removed 2 to 3 days after satisfactory voiding. All patients were followed up at $6^{\text {th }}$ and $12^{\text {th }}$ week. During follow up cosmetic outcome and surgical complications like meatal stenosis, urethrocutaneous fistula were observed. During post operative follow up meatus was examined by introducing age specific BMI feeding tube through meatus to assess meatal stenosis. Any tightness or failure to pass through meatus was regarded as meatal stenosis. Cosmetic outcome was evaluated by shape of the meatus and penile deviation or deformity. Cosmetic outcome was graded as follows:

Good: Presence of vertical slit like meatus and absence of any penile deviation or deformity

Acceptable: Presence of either abnormal meatal shape or penile deviation.

Poor: Presence of both abnormal meatal shape and penile deviation.

All the collected data were compiled and statistically analyzed with SPSS-16.

Age specific BMI feeding tube for assessing meatal size ${ }^{2}$

\begin{tabular}{ll}
\hline Age & Feeding tube size \\
\hline$<1$ year & 6 Fr feeding tube \\
$1-3$ years & 7 Fr feeding tube \\
$4-10$ years & 8 Fr feeding tube \\
$11-12$ years & 10 Fr feeding tube \\
$>12$ years & 12 Fr red-rubber catheter \\
\hline
\end{tabular}

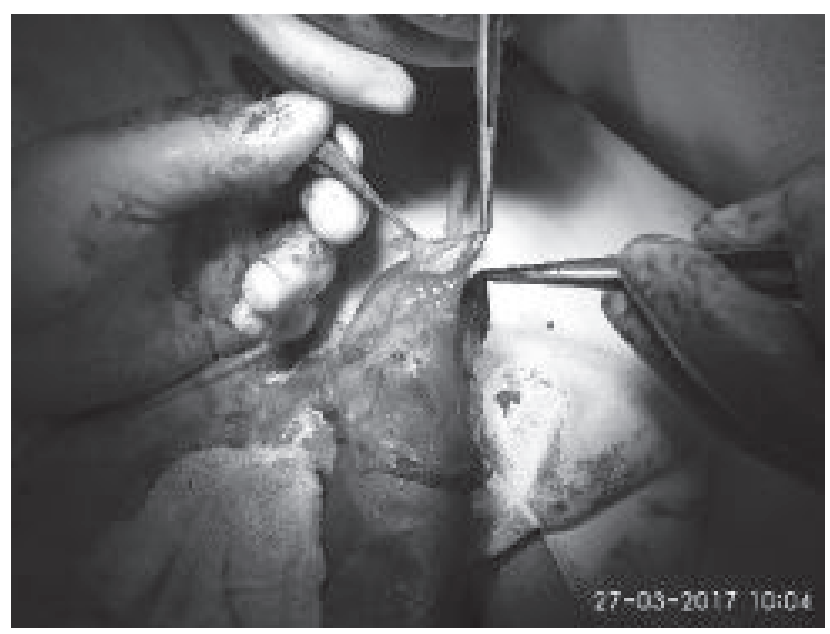

Fig.-1: Prepuceal Island Flap 


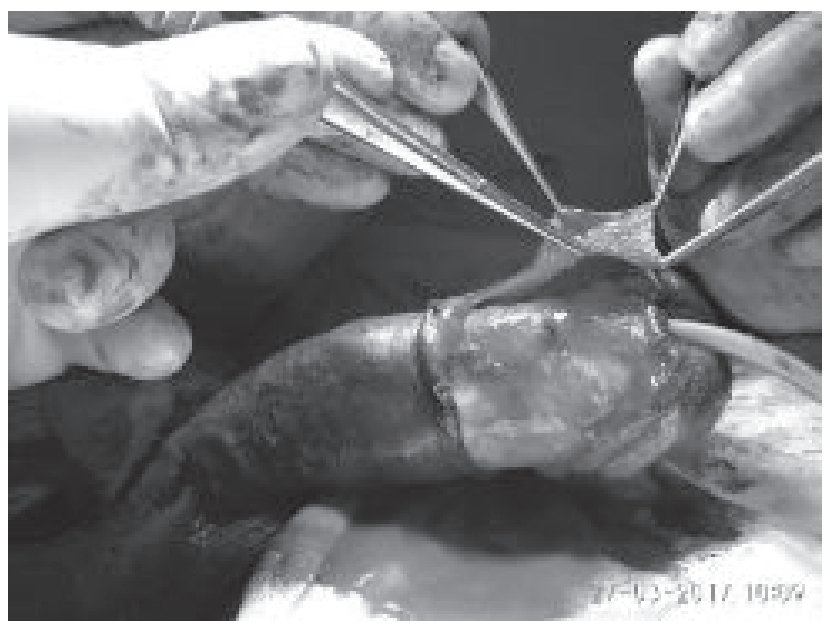

Fig.-2: Placement of flap over urethral plate

\section{Results:}

A total of 18 patients of distal penile hypospadias were operated by transverse preputial island flap urethroplasty methods during this study period. Three patients were dropped out during follow up period. The different parameters of the rest of the patients have been shown in tabulated form and statistically analyzed.

Among 15 patients, age range from 1 to 14 years with mean age 8.12 years. The age distribution is given in table 1.

Table-I: Distribution of the patients according to age.

\begin{tabular}{lcc}
\hline Age (in year) & Number of Patients & Percentage \\
\hline$<2$ & 1 & 6.7 \\
$2-5$ & 3 & 20 \\
$5-8$ & 5 & 33.3 \\
$8-11$ & 3 & 20 \\
$11-14$ & 3 & 20 \\
\hline Total & 15 & 100 \\
\hline
\end{tabular}

Table-II: Distribution of the patients according to position of EUM.

\begin{tabular}{lcc}
\hline Position of EUM & No. of Patients & Percentage \\
\hline Sub-coronal & 4 & 26.7 \\
Distal penile & 11 & 73.3 \\
\hline Total & 15 & 100 \\
\hline
\end{tabular}

Table II shows, external urethral meatus were subcoronal in $4(26.7 \%)$ case and distal penile $(73.3 \%)$ of case.

Table-III: Distribution of the patients by post-operative complication.

\begin{tabular}{lcc}
\hline Complications & No. of patients & Percentage \\
\hline Wound disruption & 1 & 6.7 \\
UCF Formation & 0 & 0 \\
Meatal stenosis & 0 & 0 \\
Wound infection & 1 & 6.7 \\
\hline
\end{tabular}

Table III showed wound disruption in the form of glandular disruption was noted in 1 patient $(6.7 \%)$. Wound infection was noted in 1 patient that was settled with antibiotics and regular dressing. In our series no patient developed urethrocutaneous fistula or meatal stenosis .

Table-IV: Distribution of the patients according to cosmetic outcome

\begin{tabular}{lcc}
\hline Cosmetic Outcome & No. of patients & Percentage \\
\hline Good & 12 & 80 \\
Acceptable & 2 & 13.3 \\
Poor & 1 & 6.7 \\
\hline Total & 15 & 100 \\
\hline
\end{tabular}

Table 4 showed that $12(80 \%)$ patients had good cosmetic appearance, $2(12.3 \%)$ patients had abnormal meatal shape and $1(6.7 \%)$ patient had noticeable penile deviation to the right side but which was less than 30 degree and require no intervention.

\section{Discussion:}

This prospective study was conducted in the department of Urology, Dhaka Medical College Hospital, during the period of 2013 to 2017 and finally fifteen patients were included and underwent transverse preputial island flap (TPIF) urethroplasty. Outcomes of the procedure were compared in terms surgical complications and cosmetic outcome.

In our series, the mean age of the patients was 8.12. Optimum time for elective surgery for hypospadias in between 6 to 12 months. ${ }^{8}$ Our study patients were older than the recommended age group. This is because of the current trend of our institution where relatively 
younger hypospadias patients attend in the Department of Pediatric Surgery. However the age range of our study is comparable to some other studies where the mean age of the patients was 84 months and 60 months. ${ }^{9,10}$

The position of EUM of most of the patients in our series was distal penile $11(73.3 \%)$, sub-coronal position in $04(16.7 \%)$. Preoperative location of meatus in hypospadias patient is found the only significant independent risk factor for development of urethrocutaneous fistula. ${ }^{11}$

Wound disruption is not an uncommon complication following hypospadias surgery especially after a flap repair. It can be technically difficult to close the skin over the bulk of pedicle of the flap, which may predispose to glandular disruption due to loss of vascularity of the overlying skin. In our series we encountered $1(6.67 \%)$ patients developed wound disruption in the form of glandular disruption. Braga et al. and Javid et al. found the rate of wound breakdown $5 \%$ and $10 \%$ respectively in onlay island flap procedure which is compatible to our study. ${ }^{12,13}$ The key to prevent wound disruption as well as overall complication is minimal tissue handling, proper mobilization of flap, tension-free reconstruction and appropriate case selection. ${ }^{14}$

Urethrocutaneous fistulae (UCF) are the most common complication of hypospadias repair with rates of up to $45 \%$ described in the literature. ${ }^{15}$ Cooper et al. and Ghali et al. did 36 and 15 cases of island onlay flap hypospadias repairs without any fistula. ${ }^{16,17}$ Liao and Smith found a rates of fistulae for onlay island flap $(9 \%) .{ }^{15}$ Singh et al. found UCF rate $5 \%$ with some modifications in original OIF repair in their consecutive 200 hypospadias patients where meatal position was coronal in 5\% cases and subcoronal in $60 \%$ cases. ${ }^{18}$ Fistula rate was nil in our study. So our study correspond to the study of Cooper et al., Liao and Smith, Ghali et al., Singh et al. The chance of fistula was less in TPIF. There were no urethrocuteneus fistula in our series probably due to less number of patients and all of them were sub-coronal and distal penile variety and meticulous surgical techniques.

Metal stenosis is one of the complications seen with urethroplasty. Meatal problems can be the cause of unsatisfactory cosmetic appearance and can also cause fistula. Technical problems such as creating a narrow lumen meatus or too tight glanuloplasty are the most common cause of meatal stenosis. In our study we focused on this precipitating cause and there was no meatal stenosis. However, we encountered meatal problem as patulous meatus in case of our one case. It may be due to larger width of the flap diameter. Usually no surgery was required.

Cosmetic appearance is one of the important primary outcomes of hypospadias surgery and usually assessed by the surgeon. We have assessed cosmetic outcome in our series as good, satisfactory and poor, keeping in mind the shape of the neomeatus and presence or absence of penile torsion. Cimador et al. also evaluated cosmetic parameters by subjective manner as good, acceptable, bad or indifferent and parameters were normal appearance of meatus (size, position and orientation), normal appearance of prepuce and parental satisfaction. ${ }^{19}$ In our series increased frequency of rounded fish-mouth shaped neomeatus and penile deviation turned the outcome poor that was $6.7 \%$. Cimador et al also shows complication rate $2.3 \% .19$

However, no hypospadias surgeon is unassailable from complications but in our study the complication rate is much lower probably due to small sample size, proper selection of patient and meticulous surgical technique play important role in minimizing postoperative complications. There are some limitations of the present study. Though we documented cosmetic and functional outcomes by physical examination and ascertaining a good stream of urine we did not perform any uroflowmetry studies. It is a single center study. Our sample size was small in number. Follow up period is very short. There may be subjective bias of the surgeon towards transverse preputial island flap.

So when question arises regarding choice of urethroplasty procedure aiming complication free good cosmetic outcome in case of distal penile hypospadias, transverse preputial island flap may be another option in compare to TIPU .

\section{Conclusion:}

Transverse preputial island flap urethroplasty delivers reliable cosmetic and functional outcomes in case of distal hypospadias. With skilled hand the outcome will be better and larger scale study is necessary.

\section{References:}

1. Erol A, Baskin L, Li Y, Liu W. Anatomical studies of the urethral plate: why preservation of the urethral plate is important in hypospadias repair. BJU International. 2001;85(6):728-734. 
2. Snodgrass W. Tubularized, Incised Plate Urethroplasty for Distal Hypospadias. Journal of Urology. 1994;151(2):464-465.

3. Snodgrass W, Lorenzo A. Tubularized incisedplate urethroplasty for proximal hypospadias. BJU International. 2008;89(1):90-93.

4. Elder JS, Duckett JW. Urethral reconstruction following an unsuccessful one stage hypospadias repair. World J Urol 1987;5:19-60.

5. Asopa HS, Elhence EP, Atri SP, Bansal NK. One stage correction of penile hypospadias using a foreskin tube. A preliminary report. Int Surg 1971;55:435-40.

6. Ansari M, Agarwal S, Sureka S, Mandhani A, Kapoor R, Srivastava A. Impact of changing trends in technique and learning curve on outcome of hypospadias repair: An experience from tertiary care center. Indian J Urol. 2016 JulSep; 32(3): 216-220.

7. Bhat A, Mandal A. Acute postoperative complications of hypospadias repair. Indian Journal of Urology. 2008;24(2):241.

8. Courtiss E, Kelali s. The timing of elective surgery on the genitalia of male children with particular reference to undescended testes and hypospadias. Plastic and Reconstructive Surgery. 1976;57(3):400.

9. Ozturk H, Onen A, Otçu S, Kaya M, Ozturk H. The outcome of one-stage hypospadias repairs. Journal of Pediatric Urology. 2005;1(4):261-266.

10. Singal A, Dubey M, Jain V. Transverse preputial onlay island flap urethroplasty for single-stage correction of proximal hypospadias. World Journal of Urology. 2015;34(7):1019-1024.

11. Chung J, Choi S, Kim B, Chung S. Risk Factors for the Development of Urethrocutaneous Fistula after Hypospadias Repair: A Retrospective Study. Korean Journal of Urology. 2012;53(10):711.

12. Braga LHP, Pippi Salle JL, Lorenzo AJ, Skeldon S, Dave S, Farhat WA, Khoury AE, Bagli DJ. Comparative analysis of tubularized incised plate versus onlay island flap urethroplasty for penoscrotal hypospadias. J Urol 2007(178):14511457

13. Javid L, Pansota MS, Ahmed I, Tariq M, Tabassum SA. Comparison between Tubularised Incised Plate Urethroplasty and Onlay Island Flap Repair in Mid and Proximal Penile Hypospadias. Journal of the Pakistan medical Association 2014(64): 4

14. Jyoti Upadhyay, Bijan Shekarriz, Antoine E. Khoury, Midshaft hypospadias, 2002, Urol Clin N Am 29 (2002) 299-310,

15. Liao A, Smith G. Urethrocutaneous fistulae after hypospadias repair: When do they occur? Journal of Paediatrics and Child Health. 2016;52(5):556560.

16. Cooper C, Noh P, Snyder H. Preservation of urethral plate spongiosum: technique to reduce hypospadias fistulas. Urology. 2001;57(2):351-354.

17. Ghali A, El-Malik E, Al-Malki T, Ibrahim A. OneStage Hypospadias Repair. European Urology. 1999;36(5):436-442.

18. Singh B, Solanki F, Kapoor R, Dassi V, Kaswan H, Agrawal V et al. Factors Predicting Success in Hypospadias Repair Using Preputial Flap With Limited Pedicle Mobilization (Asopa Procedure). Urology. 2010;76(1):92-96.

19. Cimador M, Pensabene M, Sergio M, Catalano P, de Grazia E. Coverage of urethroplasty in pediatric hypospadias: Randomized comparison between different flaps. International Journal of Urology. 2013; 20:1000-1005 